\title{
Application of legal principles and medical ethics: multifetal pregnancy and fetal reduction
}

\author{
May Anne Cheong ${ }^{1}$, MBBS, Catherine Swee Kian Tay², LLB, LLM
}

\begin{abstract}
In the management of complex medical cases such as a multifetal pregnancy, knowledge of the ethical and legal implications is important, alongside having competent medical skills. This article reviews these principles and applies them to scenarios of multifetal pregnancy and fetal reduction. Such a discussion is not solely theoretical, but is also relevant to clinical practice. The importance of topics such as bioethical principles and informed consent are also herein addressed.
\end{abstract}

Keywords: assisted reproductive technology, fetal reduction, medical ethics, medicolegal, multifetal pregnancy

\section{INTRODUCTION}

Legal concepts of informed consent and ethical theories are universal and applicable to a variety of situations. To most clinicians, legal and ethical principles may be considered an academic indulgence due to the gap between such principles and clinical practice. However, the approach to many clinical problems requires a certain degree of knowledge and application of medical ethics and the law.

The incidence of multifetal pregnancies has increased over the last few decades - largely a result of assisted reproductive technology (ART). (1) This is significant as the rates of fetal and maternal complications are higher in multifetal pregnancies, with this risk increasing with the number of fetuses. This trend has necessitated the development of fetal reduction to manage multifetal pregnancies, in order to improve perinatal survival and reduce maternal risk. Although fetal reduction techniques have emerged to be effective in improving pregnancy outcomes, this has been an area of great controversy where ethical and legal issues have not been clearly addressed. While individual doctors reserve the right of conscientious objection, one should be aware of the issues surrounding this complex subject matter, so as to be able to better manage and counsel patients. This approach may be applied to similar medical dilemmas with ethical and legal implications.

\section{BACKGROUND Epidemiology}

The natural incidence of twins and triplets is 1 in 80 and 1 in 8,000 pregnancies, respectively. ${ }^{(2)}$ The general trend over the past two decades is an increased incidence of multifetal pregnancies. ${ }^{(3)}$ This is largely attributed to the widespread use of ART - a collective term for procedures aimed at increasing a woman's probability of becoming pregnant - which comprises in vitro fertilisation and ovulation stimulation. ${ }^{(4)}$

\section{Consequence}

The increase in the incidence of multifetal pregnancies is of much concern, as this also increases the morbidity and mortality of both the mother and fetuses. ${ }^{(5)}$ Generally, perinatal and maternal risks are proportional to the number of fetuses. ${ }^{(6)}$ The most serious risks include complete pregnancy loss and prematurity, which may lead to potential short-term sequelae such as respiratory and gastrointestinal complications, and long-term neurological impairment. ${ }^{(7)}$ The maternal medical risks associated with multifetal pregnancy include hyperemesis, gestational diabetes mellitus, preeclampsia and postpartum haemorrhage, which if severe may be life-threatening to the mother and have a secondary impact on fetal outcome. ${ }^{(8)}$

Furthermore, the economic and psychosocial impact of multiple births on the patient and family has to be acknowledged. ${ }^{(9)}$ The short-term physical and emotional demands of caring for an infant are compounded in multifetal pregnancies and superimposed with higher incidences of medical and developmental issues. The economic and social burden of multifetal pregnancy on the family cannot be belittled. ${ }^{(10)}$

\section{Fetal reduction}

Fetal reduction may be indicated in various circumstances. In selective termination, (one or more) anomalous fetuses in a multifetal pregnancy are terminated. In contrast, multifetal pregnancy reduction (MFPR) reduces the number of fetuses in gestation in order "to improve the chances of healthy survival in the remaining conceptuses and to reduce the hazards to the mother". ${ }^{(11)}$ Apart from optimisation of outcome, fetal reduction may be conducted for social reasons based on the patient's request. The 2006 International Federation of Gynecologists and Obstetricians (FIGO) Committee Report stated that "multiple pregnancies of an order of magnitude higher than twins involves great danger for the woman's health and also for her fetuses, which are likely to be delivered prematurely with a high risk of either dying or suffering damage," and that "where such pregnancies arise, it may be considered ethically preferable to reduce the number of fetuses rather than to do nothing". ${ }^{(12)}$

Assessment of the fetus for genetic abnormalities via chorionic villus sampling is performed prior to the decision to proceed with fetal reduction. Fetal reduction is preferably performed

${ }^{1}$ Yong Loo Lin School of Medicine, ${ }^{2}$ School of Business, National University of Singapore, Singapore

Correspondence: A/Prof Catherine Tay Swee Kian, 32 Sunset View, Singapore 597194. biztayc@nus.edu.sg 
between 10 and 13 weeks of gestation, with the transabdominal approach most commonly undertaken. Ultrasonography-directed percutaneous intracardiac injection of potassium chloride is performed using a 20-gauge needle. ${ }^{(13)}$ In MFPR, where there is no absolute indication for fetal selection, an objective approach should be developed through the use of morphological and chromosomal analyses prior to fetal reduction. ${ }^{(14)}$ Selection criteria include investigation to ascertain growth retardation, morphological malformation and chromosomal anomalies, amid other technical considerations. ${ }^{(15)}$

Pregnancy outcome is improved when higher-order multifetal gestations are reduced. ${ }^{(16)}$ Fetal reduction has been shown to decrease the incidence of miscarriage, prematurity and lowbirth-weight infants. However, fetal reduction intervention also has inherent risk, with recent series citing an overall pregnancy loss rate of $4.7 \% .^{(17)}$

\section{REVIEW OF LEGAL PRINCIPLES AND MEDICAL ETHICS Bioethical principles}

Autonomy, beneficence, non-maleficence and justice are the four guiding bioethical principles. Autonomy respects the ability of the individual to make decisions on their own health and future. The principle of beneficence obliges a doctor to perform actions intended to benefit patients or others. Non-maleficence refers to the duty to do no harm and not kill. Justice implies equity and fair distribution of benefits and burdens.

\section{Informed consent}

Consent is an ethical principle and has been stressed in the recent case of Chester $v$ Afshar. ${ }^{(18)}$ Based on the ethical concept of patient autonomy, the patient reserves the right to know and decide. Hence, it is a doctor's medical duty of care to obtain valid informed consent. This implies full and voluntary disclosure, with the standard laid down by the Bolam test. ${ }^{(19)}$ As underlined by Bolam's test, a doctor is required to disclose what the current accepted practice is. This practice has to have a logical basis, as stated in the Bolitho case. ${ }^{(20)}$

\section{Ethical theories}

Derived from the Greek word deon, which means 'duty', deontology primarily concerns the intention to fulfil one's duties. This implies that as a doctor to a patient, one assumes a duty of care to the patient, which encompasses various aspects, with the ultimate aim of safeguarding the welfare of the patient. Utilitarianism judges an action in terms of the how the action maximises the amount of pleasure or happiness (or desiresatisfaction) for a maximum number of people. As such, actions are deemed right or wrong according to the consequences.

\section{APPLICATION OF LEGAL PRINCIPLES AND MEDICAL ETHICS}

Complex and multifaceted medical issues such as fetal reduction necessitate deeper discussion. Since the inception of fetal reduction, the procedure has been questioned based on ethical and legal considerations. Although fetal reduction techniques are widely employed in multifetal pregnancies, there are many issues regarding its legality because statutes pertaining to the matter are ambiguous and do not directly address components of the techniques. This ambiguity is largely due to the inevitable gap that arises when the legal system fails to keep pace with technological advancements. ${ }^{(21)}$ Thus, serving as the backbone for development of legal and moral standards, medical ethics compensate for this deficit. However, it should be noted that law and ethics may not be in mutual agreement; ethical practice may be considered illegal and vice versa.

\section{Legal interpretation}

The legal definition of fetal reduction remains ambiguous in the Singapore context. Although there are similarities between fetal reduction and abortion (both procedures result in the death of a fetus), resulting in both procedures facing common ethical issues, the two procedures should not be considered legally equivalent. Recognising the differences between fetal reduction and abortion will warrant the latter procedure's exclusion from strict regulations. ${ }^{(22)}$ Fetal reduction and abortion are not equivalent - the primary objective of fetal reduction is to reduce the number of fetuses, not the termination of pregnancy. Hence, the issues presented in such a context differ from the legal and ethical discussion of abortion. The fundamental difference between the two procedures is that of intent. A patient undergoing abortion intends to end the entire pregnancy. In contrast, a woman undergoing fetal reduction does not desire termination of the pregnancy, but rather optimisation for a better pregnancy outcome. $^{(23)}$

\section{Ethical theories}

According to Beauchamp and Childress, "Principles, rules, professional obligations and the issue of rights often need to be balanced in the process of finding reasons to support beliefs about which moral norms should prevail."(24) The ethical issues surrounding fetal reduction are many and should be addressed in order to justify and develop standards in medical practices with regard to this procedure. Multifetal pregnancy presents somewhat like the quintessential lifeboat dilemma where all will suffer if nothing is done, but some will have to die for others to live. Hence, herein arises the basic question constantly tackled by philosophers and others: is it ever right to do harm to one to benefit another?

Two ethical theories, though intrinsically opposing each other, are relevant in addressing this issue, utilitarianism and deontology. ${ }^{(25)}$ Drawing analogies from the following two cases, we attempt to illustrate the predicament at hand. The British case, The Queen v Dudley \& Stephens established precedent that necessity is not a defence to a charge of murder either on the basis of legal precedent or ethics and morality. The case concerned a shipwreck victim who, in order to escape death from hunger, killed another for the purpose of survival cannibalism. This demonstrates the rejection of utilitarianism establishing that necessity does not justify the sacrifice of another. In contrast, in the American Case, United States v Holmes, though sailors were 
found guilty for throwing passengers overboard to save others, it was recognised that necessity was a possible justification, hence accepting the utilitarian viewpoint. ${ }^{(26,27)}$

\section{Informed consent}

A patient having a triplet pregnancy reserves the right to decide for herself whether or not to proceed with the pregnancy. This patient autonomy is based on the ethical concept of autonomy, and a consequence of this principle is the doctrine of informed consent. The decision for fetal reduction is typically based on the patient's moral construct and health beliefs. In Singapore, patients may lawfully request for the reduction of pregnancy; there is no grounds for refusal except in cases where the physician states his/ her own conscientious objection. However, the legality of fetal reduction is limited to cases where there is no violation of the law (i.e. fetal reduction for purely social and financial reasons is not allowed). ${ }^{(28)}$ Informed consent of the intended procedure needs to be valid - this is part of a doctor's medical duty of care.

The risks of medical procedures should be communicated to the patient to facilitate decision-making. The sufficiency of information conveyed can be determined using the Bolam test, where adequacy is assessed by a responsible body of medical men. In cases where the cause of the situation is iatrogenic, the importance of informed consequence arises from the initial offered medical procedure. Hence, the possibility of complications in a multifetal pregnancy should be made known at this stage. This may extend to disclosure of the option and implications of fetal reduction in a multifetal pregnancy, including disclosure of the risk to mother and fetuses, with or without reduction. ${ }^{(29)}$ As such, an in-depth discussion weighing the risks and benefits of such a procedure between the patient and the doctor is needed. A doctor may be found negligent if the risks of multifetal pregnancy were not explained adequately at the commencement of fertility treatment and if the doctor fails to offer the option of reduction when faced with multifetal pregnancy. In an American case in which only three fetuses in a set of septuplets survived (of these, two are severely handicapped), Evans et al state that malpractice litigation pertaining to inadequate disclosure of the risks of multifetal pregnancy and the option of fetal reduction has been instituted in the United States. ${ }^{(30)}$

Neither the decision to reduce the number of fetuses and to continue a multifetal pregnancy nor its consequences are simple. Complexity stems from the emotional and psychological toll of a decision that requires consideration based on medical, social or economic factors. Psychological ramifications such as guilt and the stress from a multifetal pregnancy and choice of fetal reduction should not be written off. It is important to address such issues with patients who are already in a volatile psychological state. Acknowledging the psychological well-being of the patient is essential as this would affect how a doctor presents the relevant information to such a patient, which may affect how the patient processes this presented data. ${ }^{(31)}$ Although there are no notable cases in the literature specific to MFPR, medical negligence relating to psycho-socio-economic aspects has been brought up in civil postabortion legal cases. ${ }^{(32)}$

\section{Other considerations}

Deciding on the number of fetuses to reduce and its selection are also a dilemma. While decisions should be made based on empirical and technical criteria, the concern of gender selection cannot be ignored. The results of pre-reduction genetic diagnosis become a major determining factor in the final decision of the fetus to reduce. However, what is problematic is that the information provided by such a test includes the gender of each fetus. Issues pertaining to gender selection are far-reaching, and as seen in many societies where there is a predilection for males over females, the widespread use of sex selection has many societal implications, such as the alteration of the population sex ratio, which has its own accompanying set of social problems. On a more fundamental level, gender selection implies that the gender selected for termination is considered inferior to the other. While some may consider the decision a component of reproductive autonomy, the general consensus is that gender selection is unethical, and in some countries illegal, to make a decision of feticide based on gender. ${ }^{(33)}$

\section{Application}

From a deontological standpoint, doctors are committed to a duty of care to both the mother and her fetus. The duty to inform is essential and multiple issues need to be addressed. It is importance for the doctor to provide information pertaining to the possible outcomes of different courses of actions (i.e. fetal reduction vs. expectant management). In the case of fetal reduction, the following may be considered: (a) the nature and process of fetal reduction; (b) expectant management as an alternative; (c) potential complications, e.g. complete pregnancy loss and the risk of expectant management; (d) the benefits of fetal reduction, i.e. reduction of maternal and fetal morbidity and mortality risks; (e) limitations of treatment; (f) success and failure rates; and (g) post-reduction precautions and management.

In maintaining patient autonomy, doctors should subordinate self-interest and minimise pejorative guidance to patients based on one's religious and ethical beliefs. Beyond the realm of informed consent, it is also important to recognise the multifaceted process of decision-making, as this enhances patientdoctor communication. This is also crucial because with better communication comes proper informed consent-taking, and claims based on perceived, rather than actual, negligence on the part of the doctor will be avoided. ${ }^{(34)}$

However, such decision-making is affected by how patients 'frame' those decisions. Framing as a process was introduced by Goffman to help resolve the problem of differential meaning in human interaction. ${ }^{(35)}$ Medical frames are characterised by a reliance on statistics regarding the outcomes and risk to the mother and her surviving fetus. This emphasises the influence of medical authorities, and are driven by a desire to minimise medical risks. This differs from moral frames. Moral frame emphasises the need to minimise infringement on the pro-life agenda that are common religious and societal doctrines. ${ }^{(36)}$ In practice, doctors need to recognise and acknowledge the patient's perception of the situation, and adopt a personalised approach to informed consent and counselling. It is imperative to acknowledge the complexity 
of cases where medical, legal and ethical perspectives have to be regarded. As such, the role of the medical ethics committee to review the case is crucial and the committee's input needs to be considered in the decision-making process.

The incidence of multifetal pregnancies is intrinsically linked with the practice of fertility medicine. Therefore, legal frameworks guiding the practice need to be in place in order to reduce the rates of multifetal pregnancies, for example, by limiting the number of embryo replacements for IVF and providing guidelines on ovulation stimulation techniques. ${ }^{(37)}$ Such measures have already been instituted in the licensing terms and conditions on assisted reproduction services imposed under section 6(5) of the Private Hospitals and Medical Clinics Act.

\section{CONCLUSION}

The management of multifetal pregnancy is difficult. While fetal reduction is a possible management option, it should not be utilised as a safety net in fertility treatment - prevention of higher-order multifetal pregnancies must be the primary objective. In addressing complex medical issues such as fetal reduction, knowledge of the relevant ethical and legal implications besides medical skill competency is important. Nevertheless, while knowledge makes for good medical practice, it is the upholding of compassion, fidelity and humanity as common denominators across time and cultures that should be the ethical aspirations of health professionals. ${ }^{(38)}$

\section{REFERENCES}

1. Chia KS, Lee JJ, Cheung P, et al. Twin births in Singapore: a populationbased study using the National Birth Registry. Ann Acad Med Singapore 2004; 33:195-9.

2. Benirschke K, Kim CK. Multiple pregnancy. N Engl J Med 1973; 288:1276-84

3. Blondel B, Kaminski M. Trends in the occurrence, determinants, and consequences of multiple births. Semin Perinstol 2002; 26:239-49.

4. World Health Organization. Current practices and controversies in assisted reproduction: report of a WHO meeting on "Medical, Ethical and Social Aspects of Assisted Reproduction". WHO; 2002.

5. Cunningham FG, Hankins GDV, et al. Multifetal Pregnancy. In: Cunningham FG, MacDonald PC, et al, eds. Williams Obstetrics. 20th ed. Connecticut: Appleton \& Lange, 1997: 861-94.

6. Jones HW, Schnorr JA. Multiple pregnancies: a call for action. Fertil Steril 2001; 75:11-3.

7. MacDorman MF, Martin JA, Mathews TJ, Hoyert DL, Ventura SJ. Explaining the 2001-02 infant mortality increase: data from the linked birth/infant death data set. Natl Vital Stat Rep 2005; 53:1-22.

8. Wen SW, Demissie K, Yang Q, Walker MC. Maternal morbidity and obstetric complications in triplet pregnancies and quadruplet and higher-order multiple pregnancies. Am J Obstet Gynecol 2004; 191:254-8.

9. Ellison MA, Hall JE. Social stigma and compounded losses: quality-of-life issues for multiple-birth families. Fertil Steril 2003; 80:405-14.

10. Bryan EM. The consequences to the family of triplets or more. J Perinat Med 1991; 19 Suppl 1:24-8.

11. Howie PW. Selective reduction: medical aspects. In: Templeton AA Cuisine DJ, eds. Reproductive Medicine and the Law. London: Churchill Livingstone, 1990: 25-32.
12. FIGO Committee for the Ethical Aspects of Human Reproduction and Women's Health. Ethical recommendations on multiple pregnancy and multifetal reduction. FIGO Committee for the Ethical Aspects of Human Reproduction and Women's Health. Int J Gynaecol Obstet 2006; 92:331-2.

13. Evans M, May M, Fletcher J. Multifetal pregnancy reduction and selective termination. In: Iff L, Apuzzio JJ, Vintzileos, eds. Textbook of Operative Obstetrics. 2nd ed. London: Pergamon Press; 1992: 67-76.

14. Stone J, Berkowitz RL. Multifetal pregnancy reduction and selective termination. In: Gall SA, ed. Multiple Pregnancy and Delivery. St Louis: Mosby-Year Book, 1996: 181-97.

15. Fasouliotis SJ, Schenker JG. Multifetal pregnancy reduction: a review of the world results for the period 1993-1996. Eur J Obstet Gynecol Reprod Biol 1997; 75:183-90.

16. Evans MI, Dommergues M, Wapner RJ, et al. International, collaborative experience of 1789 patients having multifetal pregnancy reduction: a plateauing of risks and outcomes. J Soc Gynecol Investig 1996; 3:23-6.

17. Stone J, Eddleman K, Lynch L, Berkowitz RL. A single center experience with 1000 consecutive cases of multifetal pregnancy reduction. Am J Obstet Gynecol 2002; 187:116-7.

18. Chester v. Afshar [2002] EWCA Civ 724; [2003] Queen's Bench Division 356.

19. Bolam v. Friern Hospital Management Committee [1957] 1 Weekly Law Reports 583.

20. Bolitho v. City and Hackney Health Authority [1997] 4 All England Reports 771

21. Knopoff KA. Can a pregnant woman morally refuse fetal surgery? Calif Law Rev 1991; 79:499-540.

22. Singapore Statutes, Termination of Pregnancy Act (Cap. 324)- 1974.

23. Nisand I, Shenfield F. Multiple pregnancies and embryo reduction: ethical and legal issues. In: Shenfield F, Sureau C, eds. Ethical Dilemmas in Assisted Reproduction. New York: Parthenon Press, 1997: 67-76.

24. Beauchamp TL, Childress JF. Principles of Biomedical Ethics. 6th ed. Oxford: Oxford University Press, 2009: xiii, 417.

25. Daar JF. Selective reduction of multiple pregnancy: lifeboat ethics in the womb. Univ Calif Davis Law Rev 1992; 25:773-843.

26. The Queen v. Dudley and Stephens, 14 Queen's Bench Division 273 (1884).

27. United States v. Holmes. Circuit Court, E. D. Pennsylvania. 26 F.Cas. 360 (1842).

28. Singapore Statutes, Private Hospitals and Medical Clinics Act (Cap. 248)Revised Edition 1999.

29. FIGO Committee for the Ethical Aspects of Human Reproduction and Women's Health. Ethical recommendations on multiple pregnancy and multifetal reduction. FIGO Committee for the Ethical Aspects of Human Reproduction and Women's Health. Int J Gynaecol Obstet 2006; 92:331-2.

30. Evan MI. Selective first-trimester termination in octuplet and quadruplet pregnancies: clinical and ethical issues. Obstet Gynecol 1988; 72:821-2.

31. Britt DW, Risinger ST, Mans M, Evans MI. Anxiety among women who have undergone fertility therapy and who are considering multifetal pregnancy reduction: trends and implications. J Matern Fetal Neonatal Med 2003; 13:271-8

32. Eller TR. Informed consent civil actions for post-abortion psychological trauma. Notre Dame Law Rev 1996; 71:639-70.

33. Purdy L. Women's reproductive autonomy: medicalisation and beyond J Med Ethics 2006; 32:287-91.

34. Tay CSK. Recent developments in informed consent: the basis of modern medical ethics. APLAR J Rheu 2005; 8:165-70.

35. Goffman E. Frame Analysis: An Essay on the Organization of Experience. Cambridge, MA: Harvard University Press, 1974

36. Britt DW, Evans WJ, Mehta SS, Evans MI. Framing the decision: determinants of how women considering multifetal pregnancy reduction as a pregnancy-management strategy frame their moral dilemma. Fetal Diagn Ther 2004; 19:232-40.

37. Directives for private healthcare institutions providing assisted reproduction services: Regulation 4 of the private hospitals and medical clinics regulations (CAP 248, REG 1).

38. Cohen MH. Toward a bioethics of compassion. Ind L Rev $1995 \cdot 28: 667-8$. 